\title{
Exergetic and Exergoeconomic Analysis and Optimization of Gas Turbine Inlet Air Cooling Systems with Absorption or Compression Chilling
}

\author{
Mohammad Reza Abedi ${ }^{1}$, Gholamreza Salehi*2, Masoud Torabi Azad ${ }^{1}$, \\ Mohammad Hasan Khoshgoftar Manesh ${ }^{3,4}$, Hossein Fallahsohi ${ }^{1}$
}

\begin{abstract}
1 Energy Systems Engineering Group, Faculty of Marine Science, Northern Tehran Branch, Islamic Azad University, Tehran, Iran.

2 Mechanical Engineering Group, Faculty of Engineering, Central Tehran Branch, Islamic Azad University, Tehran, Iran. Email: rezasalehi20@gmail.com

3 Energy, Environment, and Biological Systems Research Lab (EEBRlab), Division of Thermal Sciences and Energy Systems, Department of Mechanical Engineering, Faculty of Technology \& Engineering, University of Qom, Qom, Iran 4 Center of Environmental Research, University of Qom, Iran
\end{abstract}

Received 7 September 2020, Revised 19 February 2021, Accepted 2 May 2021

\begin{abstract}
The present paper aims to study the effect of cooling air inlet methods on gas turbine compressors on increasing their efficiency. After modeling gas turbine cycles with absorption and compression systems in the EES software, these cycles' performance is investigated for all equipment of the cycle from thermodynamic, exergy, and exergoeconomic aspects. In the absorption system, the conventional solution of lithium bromide-water is used as a two-component fluid, and in the compression cycle, the R134a operating fluid is used. According to the results, with the rise in the system's inlet air temperature, the total output work of the gas turbine decreases. Based on the exergoeconomic analysis, the exergy destruction cost dominates the initial cost, resulting in the exergoeconomic factor's decline. Relationship predicted by Group Method of Data Handling (GMDH) to reduce the computation time of optimization. The studied systems are then subjected to two-objective optimization by the Particle Swarm algorithm using MATLAB software. The objective functions are related to the exergy efficiency and total cost rate. The results reveal contradictory behavior in these two objective functions so that with the increase in the exergy efficiency, the total cost rate increases.
\end{abstract}

Keywords: Gas turbine; cooling; energy; exergy; optimization; exergoeconomic; particles swarm algorithm.

\section{Introduction}

A gas turbine's performance relies on the intake air temperature so that it will decrease by about 0.64 percent per any degree increase in the temperature of the intake air versus the standard. So, the cooling of the air entering a plant can be an approach to increasing the efficiency of the plant. There are various ways to cool the intake air, such as fog or media-based evaporative cooling and compression and absorption cooling.

By including an absorption cooling system in the input of a gas turbine cycle and steam injection into the cycle, Bartolini and Salvi [1] reported an $8 \%$ increase in the output power and a $4 \%$ increase in the thermal efficiency. By placing an indirect evaporative cooling system in the compressor (intermediate cooling), A M Bassily [2] recorded a 3\% increase in inefficiency. He also investigated the effect of the evaporative cooling in the input and output of the compressor in the gas turbine cycle and found an $11 \%$ increase in the output power and an over $3.5 \%$ increase in the efficiency of the cycle [3]. In a study on fog-based cooling and its effects on the performance of a gas turbine, [4] analyzed the environmental conditions and concluded that at an air temperature of $40^{\circ} \mathrm{C}$, the reduction of the temperature by the fog system increased the power of the turbine by $8 \mathrm{MW}$, i.e., 10\%. Hosseini et al. [5] explored Fars Power Plant's combined cycle using an evaporative media system. The results indicated that under $38^{\circ} \mathrm{C}$ air temperature and $8 \%$ relative humidity, each unit's power would increase by $14.6 \%$, i.e., $11.2 \mathrm{MW}$, for $19^{\circ} \mathrm{C}$ decreases in the temperature of the inlet air by the evaporative method. Studying an evaporative cooling of inlet air, [6], [7] observed a 2-4 percent increase in the net power associated with the climate conditions. Based on the results, they observed that the application of evaporative inlet air cooling could be useful in hot and arid climates.

Alhazmy and Najjar [8] addressed the variations in the output power with the changes in the inlet air temperature using an absorption cooling based on aqua-ammonia cooling and stated that the method would increase the output power by $21.5 \%$ versus the system lacking cooling. Boonnasa et al. [9] found that applying an absorption chiller to cool intake air could improve the power of the gas turbine by about $10.6 \%$ and the power of the plant by about $6.24 \%$. The financial analysis estimated payback of about 3.81 years.

Amery and Hejazi studied the effect of using an absorption cooling system to raise the Chabahar Power Plant's capacity. Results showed that this could increase the system's output power by approximately $11.3 \%[10]$.

Behafarid and Bahodori studied performance analysis of a gas turbine equipped with inlet air cooling using an aquifer thermal energy storage [11]. Dawoud et al. [12] focused on studying the effect of an aqua-ammonia absorption cycle to 
cool the intake air. They reported that when the inlet air temperature was reduced from $25^{\circ} \mathrm{C}$ to $5^{\circ} \mathrm{C}$, the output power was increased by $22 \%$. Farzaneh and Dashtebayaz [13] compared the media and absorption chilling methods applied to the inlet air of a turbine. The results revealed that the absorption chiller's use significantly increased the efficiency and cycle power by decreasing the inlet temperature compared to the media method. Sanaye et al. [14] examined a combined CCHPW power plant. The results indicated that the temperature was $18.5^{\circ} \mathrm{C}$ in the plant's optimal design, which enhanced the exergy efficiency by $30.7 \%$, and the payback period was determined to be about 4.38 years. Baghernejad et al. [15] presented an optimal exergoeconomic model to integrate solar energy into a threedimensional power generation, heating, and cooling system. The system would reduce the unit cost of the products by $11.5 \%$ and increase the exergy efficiency from $44.38 \%$ at the base state to $56.07 \%$ at the optimal state.

Liu and Wang [16] studied the performance of a $\mathrm{LiBr}-\mathrm{H}_{2} \mathrm{O}$ absorption chiller using solar energy. Malewski and Holldorff [17] analyzed the exhaust's thermal energy gas of a gas turbine in an absorption chiller. The usage of absorption and compression refrigeration systems to cool the inlet air of a gas turbine was explored by Sanaye et al. [18], in which the impacts of these systems on the performance of the gas turbine were analyzed under the climatic conditions of Shiraz and Bandar Imam Khomeini (BIK), Iran from the technical and economic perspectives. According to the results, in the climatic conditions of $\mathrm{BIK}$ with a temperature of $49^{\circ} \mathrm{C}$ and relative humidity of $60 \%$, a $10^{\circ} \mathrm{C}$ temperature of the intake air can increase the power of the gas turbine by $38.3 \%$, whereas it will increase the power of the turbine by $24.3^{\circ} \mathrm{C}$ in the climatic conditions of Shiraz with a temperature of $40^{\circ} \mathrm{C}$ and relative humidity of $40 \%$. In 2002 and 2004, two Italian researchers defined two distinct objective functions to minimize the production cost and maximize the system's total exergy efficiency and employed an evolutionary algorithm for multi-objective optimization [19], [20].

Also, [21] conducted a research study on optimizing a power plant's economic exergy using a new optimization method. They reported valuable results by comparing the cost of production and maintenance of the power plant components with fuel consumption.

Ibrahim and Rahman investigated optimum combined cycle efficiency enhancements based on an Intercooler- reheated gas turbine [22]. Thermodynamic modeling of a transformed combustion gas turbine plant in which the Brayton refrigeration cycle was used for inlet air cooling and after cooling with evaporation has been investigated by Khaliq et al. [23]. Exergy assessment was coupled with emission calculation to determine the effects of operating parameters thermodynamically and environmentally.

Comparative evaluation of different inlet air cooling systems consisting of solar energy to promote gas turbine combined cycles in hot conditions has been investigated by Rahman and Mokheimer [24]. Results showed the increase in the net power through fogging, and evaporative cooling is less than that gained with chillers due to the limitation of the wet-bulb temperature.

Transient modeling of an intercooler regenerative-reheat gas turbine plant in the electric vehicle was performed by Nader et al. [25]. Protentional fuel consumption reduction was evaluated. As shown in the previous studies, there is no work on multi-objective optimization of inlet air cooling system absorption chiller and compression system based on exergetic and exergoeconomic objectives.

Exergoeconomic evaluation and optimization of a novel inlet air cooling system with gas turbine engines by considering cascaded waste-heat recovery have been performed by Najjar and Abubaker [26].

Morini et al. investigated the inlet air cooling of gas turbines through liquid nitrogen spray[27]. They found humidity condensation may form via fog which supplies further power augmentation.

The utilizing gas turbine inlet air cooling (TIAC) technologies in Riyadh, Saudi Arabia, have been studied by Baakeem et al.[28]. Results determined that the optimum cooling air temperature was $8^{\circ} \mathrm{C}$. Also, the best improvement is indicated on a multistage compressor with a wet condenser.

Mazhari et al. focused on the techno-economic study of using different air inlet cooling systems for gas compressor stations with $25 \mathrm{MW}$ gas turbine in Iran [29]. In the other study, Khoshgoftar Manesh et al. performed a technoeconomic analysis of different cooling systems in warm, dry $\&$ wet climate conditions at various gas stations in Qom and Asaluyeh pipeline gas stations[30].

Kwon et al. evaluated the performance enhancement of gas turbine combined cycle by dual cooling of the inlet air and turbine coolant by an absorption chiller [31]. Results indicated a more significant power boost effect than any other cooling options. Also, Economic analysis showed high applicability of the dual cooling scheme.

Sadighi Dizaji focused on an integrated Maisotsenko cooler and absorption chiller for the gas turbine's inlet air cooling. The new cycle can be used for real applications [32].

Majdi Yazdi et al. evaluated the gas turbine's inlet air cooling systems for several climates in Iran using 4E analyses [33]. Four cities in Iran candidate for different climatic conditions, Bandar Abbas (hot-humid), Ardabil (cold-humid), Yazd hot-arid), and Sari (humid subtropical).

The results indicate that the best cooling system for hot climates is the absorption chiller; it enhances gas turbine net power by $18 \%$ in Bandar Abbas and 14\% in Yazd. The inlet fogging system applies well only in an arid climate. The cold climates cooling system is applied only for a limited period, and the heat pump system is suitable.

Cha et al. investigated the Inlet air cooling and recovering system in gas turbine and $\mathrm{CO} 2$ combined cycle by cold energy from LNG based on thermodynamic analysis [34]. The proposed plant determines improvement of power generation by $25.4 \%$ and efficiency by $11.5 \%$.

Hashmi et al. investigated fouling and inlet air cooling's combined effect on different gas turbine performance for industrial applications [35].

As seen in the literature review, there was no study about the inlet air cooling system's multi-objective optimization based on absorption and compression system with maximum exergetic efficiency and minimum total exergetic cost rate. This paper aims to study the effect of absorption and compression systems for cooling air inlet to gas turbine compressors on increasing their efficiency and improve exergetic cost. In this study, the inlet air cooling system's optimization is performed by considering two-objective functions by the Particle Swarm algorithm.

For the first time, the Group Method of Data Handling (GMDH) was applied to predict the objective function in power plant systems, including exergetic efficiency and 
exergetic cost rates because of reducing computation time of two objective optimizations.

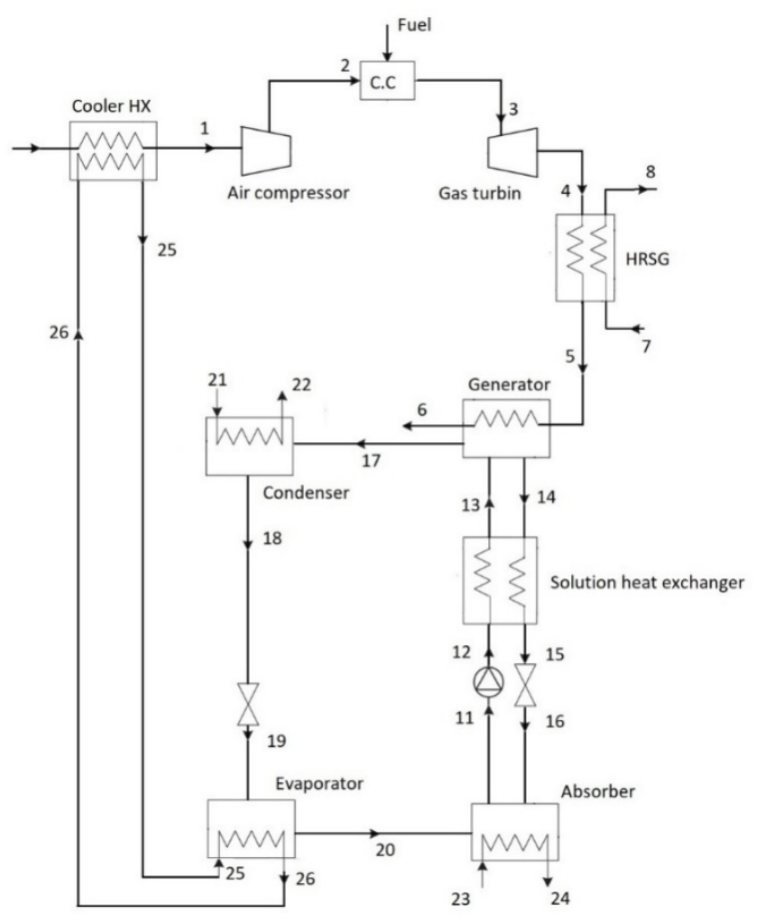

Figure 1a. Cooling with an absorption chiller (Config. 1)

\section{The studied cycles}

Figure 1 depicts the schematic outline of the combined system equipped with an absorption chiller (Config. 1), and Figure 2 shows the system equipped with a compression chiller (Config. 2). As is evident, the intake air is first cooled down to the air mixture's saturation point. As the temperature is reduced further, the air's specific humidity is also decreased so that it reaches the standard temperature of $15^{\circ} \mathrm{C}$. The compression cycle in Figure 1a that works with the working fluid R134a is similar to the absorption cycle. The only difference is that instead of the set of a generator, absorber, solution heat exchanger, pump, and solution pressure reducing valve, the output fluid of the evaporator is taken to the upper pressure of the cycle by a compressor, and electricity is the actuator of the cycle instead of a lowtemperature hot fluid actuator. The gas turbine's waste gases in Config. 2 (see Figure 1b) are only used in the steam generator to enhance the efficiency of the energy conversion system. The initial input values for the simulation of the

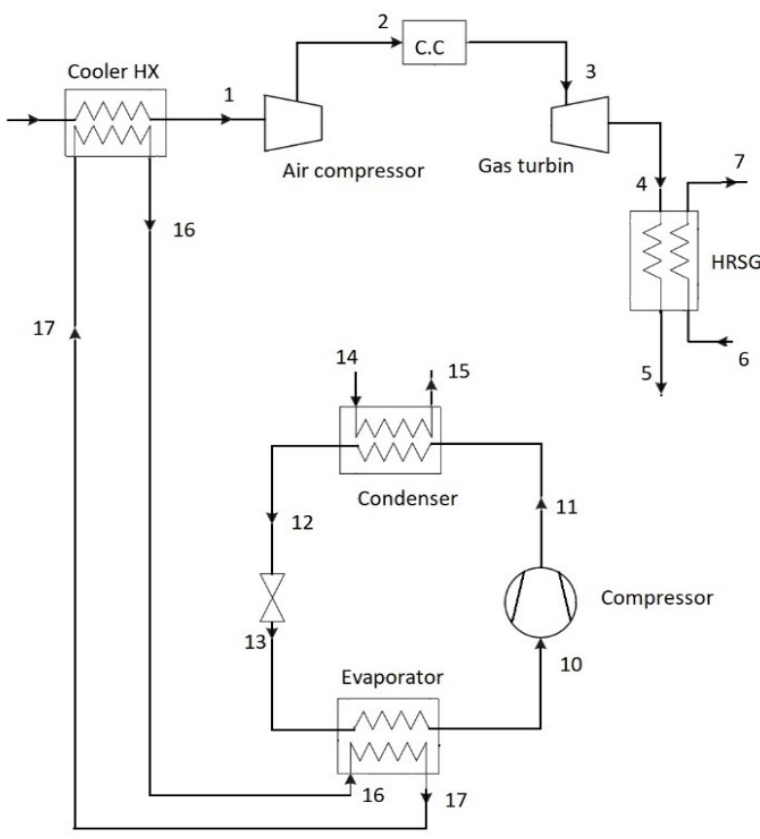

Figure 1b. Cooling with a compression chiller (Config. 2)

absorption refrigeration cycle and initial values for exergyeconomic analysis are presented in Table 1.

\section{Thermodynamic and Exergy-economic analysis of combined systems}

The different flows in the combined system are numbered according to Figures $1 \mathrm{a}$ and $1 \mathrm{~b}$, and the properties of the mixture of gases are calculated as per the mass according to the principles of an ideal gas by multiplying the mass fraction of a certain component in the property of each ideal gas component. In the cooling heat exchanger, the air is fed with a high temperature and specific humidity, where the cold fluid reduces its temperature and humidity.

The flows equivalent to the fuel and product exergy in different components of the combined system are presented in Table 2. The main and auxiliary equations for the main component are in table 3. The Initial cost of the main component is in table 4 .

Table 1. The initial input values for the simulation of the studied systems

\begin{tabular}{|c|c|c|c|c|c|}
\hline \multicolumn{4}{|c|}{ Simulation parameters } & \multicolumn{2}{|c|}{ exergy-economic parameters } \\
\hline Symbol & Value & Symbol & Value & Parameter & Value \\
\hline$t_{\mathrm{abs}}\left({ }^{\circ} \mathrm{C}\right)$ & 35 & $\dot{\bar{V}}_{\text {air,in }}\left(\mathrm{m}^{3} / \mathrm{s}\right)$ & 234 & $\varphi$ & 1.06 \\
\hline$t_{\mathrm{gen}}\left({ }^{\circ} \mathrm{C}\right)$ & 85 & $t_{a i r, i n}\left({ }^{\circ} \mathrm{C}\right)$ & 45 & $N(h r)$ & 7446 \\
\hline$t_{\text {con }}\left({ }^{\circ} \mathrm{C}\right)$ & 35 & $p_{\text {air }, \text { in }}(k P a)$ & 101.3 & $i(\%)$ & 10 \\
\hline$t_{\text {eva }}\left({ }^{\circ} \mathrm{C}\right)$ & 6 & $R H_{\text {air,in }}(\%)$ & 70 & $n($ year $)$ & 20 \\
\hline$\eta_{p}$ & 0.95 & $r_{p, \text { air }, \text { com }}$ & 10 & & \\
\hline$\varepsilon_{h x}$ & 0.7 & $\eta_{\text {air,com }}, \eta_{\text {gas,tur }}$ & 0.86 & & \\
\hline$t_{\mathrm{cw}, \text { in }}\left({ }^{\circ} \mathrm{C}\right)$ & $t_{\mathrm{abs}}-8, \quad t_{\mathrm{con}}-8$ & $t_{3}\left({ }^{\circ} \mathrm{C}\right)$ & 800 & & \\
\hline$t_{\mathrm{cw}, \text { out }}\left({ }^{\circ} \mathrm{C}\right)$ & $t_{\mathrm{abs}}-3, t_{\mathrm{con}}-3$ & $L H V(k J / k m o l)$ & 802361 & & \\
\hline$t_{\mathrm{chw}, \mathrm{in}}\left({ }^{\circ} \mathrm{C}\right)$ & $t_{\mathrm{eva}}+8$ & $t_{\text {fuel }}\left({ }^{\circ} \mathrm{C}\right)$ & 25 & & \\
\hline$t_{\text {chw, out }}\left({ }^{\circ} \mathrm{C}\right)$ & $t_{\mathrm{eva}}+3$ & $P_{\text {fuel }}(k P a)$ & 1200 & & \\
\hline
\end{tabular}


Table 2. Fuel and product exergy flows in different components of the combined cycle

\begin{tabular}{|c|c|c|}
\hline Component & Fuel exergy & Product exergy \\
\hline Cooling heat exchanger & $\dot{E} x_{25}-\dot{E} x_{26}$ & $\dot{E} x_{\text {air,out }}-\dot{E} x_{\text {air,in }}$ \\
\hline Gas compressor & $\dot{W}_{\text {air }, \text { com }}$ & $\dot{E x_{2}}-\dot{E} x_{1}$ \\
\hline Combustion chamber & $\dot{E} x_{f u e l}+E x_{2}$ & $\dot{E} x_{3}$ \\
\hline Gas turbine & $E x_{3}-E x_{4}$ & $\dot{W}_{\text {gas,tur }}$ \\
\hline Steam generator & $\dot{E} x_{4}-\dot{E} x_{5}$ & $\dot{E} x_{7}-\dot{E} x_{8}$ \\
\hline Absorption generator & $\dot{E} x_{5}-\dot{E} x_{6}$ & $\dot{E} x_{14}+\dot{E} x_{17}-\dot{E} x_{13}$ \\
\hline Absorption condenser & $\dot{E} x_{17}-\dot{E} x_{18}$ & $E x_{22}-\dot{E} x_{21}$ \\
\hline Absorption evaporator & $E x_{20}-E x_{19}$ & $\dot{E} x_{25}-\dot{E} x_{26}$ \\
\hline Absorption absorber & $\dot{E} x_{16}+\dot{E} x_{20}-\dot{E} x_{11}$ & $\dot{E} x_{24}-\dot{E} x_{23}$ \\
\hline Solution heat exchanger & $\dot{E} x_{14}-\dot{E} x_{15}$ & $\dot{E} x_{13}-\dot{E} x_{12}$ \\
\hline Solution pump & $\dot{w}_{\mathrm{sp}, \mathrm{ACH}}$ & $\dot{E} x_{12}-\dot{E} x_{11}$ \\
\hline
\end{tabular}

Table 3: main and auxiliary equations

\begin{tabular}{|c|c|c|}
\hline component & Main equation & auxiliary equations \\
\hline cooler & $c_{\text {air }, \text { in }} \dot{E} x_{\text {air }, \text { in }}+c_{26} \dot{E} x_{26}+\dot{Z}_{\text {Cooler }, H X}=c_{1} \dot{E} x_{1}+c_{25} \dot{E} x_{25}$ & $\begin{array}{l}c_{14}=c_{15} \\
c_{\text {air }, \text { in }}=0\end{array}$ \\
\hline compressor & $c_{1} \dot{E} x_{1}+c_{e l, g a s} \dot{W}_{g a s, c o m}+\dot{Z}_{g a s, c o m}=c_{2} \dot{E} x_{2}$ & $c_{1}=0$ \\
\hline $\begin{array}{l}\text { combustion } \\
\text { chamber }\end{array}$ & $c_{2} \dot{E} x_{2}+c_{f u e l} \dot{E} x_{f u e l}+\dot{z}_{c c}=c_{3} \dot{E} x_{3}$ & $c_{\text {fuel }}=12\left(\frac{\$}{G j}\right)$ \\
\hline gas turbine & $c_{3} \dot{E} x_{3}+\dot{Z}_{g a s, t u r}=c_{e l, g a s} \dot{W}_{g a s, t u r}+c_{4} \dot{E} x_{4}$ & $c_{3}=c_{4}$ \\
\hline steam generator & $c_{4} E x_{4}+c_{7} \dot{E} x_{7}+\dot{Z}_{H R S G}=c_{5} \dot{E} x_{5}+c_{8} \dot{E} x_{8}$ & $c_{4}=c_{5}$ \\
\hline absorption generator & $\begin{aligned} c_{5} \dot{E} x_{5}+c_{13} \dot{E} x_{13}+\dot{Z}_{g e n, A C H} & =c_{6} \dot{E} x_{6}+c_{14} \dot{E} x_{14}+c_{17} \dot{E} x_{17} \\
\frac{c_{14} E x_{14}-c_{13} \dot{E} x_{13}}{E x_{14}-E x_{13}} & =\frac{c_{17} E x_{17}-c_{13} \dot{E} x_{13}}{E x_{17}-E x_{13}}\end{aligned}$ & $c_{5}=c_{6}$ \\
\hline $\begin{array}{l}\text { Solution heat } \\
\text { exchanger }\end{array}$ & $c_{12} \dot{E} x_{12}+c_{14} \dot{E} x_{14}+\dot{Z}_{s h x, A C H}=c_{13} \dot{E} x_{13}+c_{15} \dot{E} x_{15}$ & $c_{14}=c_{15}$ \\
\hline thermal pump & $c_{11} \dot{E} x_{11}+c_{e l} \dot{W}_{s p, A C H}+\dot{Z}_{s p, A C H}=c_{12} \dot{E} x_{12}$ & $c_{e}=0.036\left(\frac{\$}{k W . h}\right)$ \\
\hline pressure-reducing & $c_{15}=c_{16} c_{18}=c_{19}$ & - \\
\hline $\begin{array}{l}\text { absorption } \\
\text { condenser }\end{array}$ & $c_{17} \dot{E} x_{17}+c_{21} \dot{E} x_{21}+\dot{Z}_{c o n, A C H}=c_{18} \dot{E} x_{18}+c_{22} \dot{E} x_{22}$ & $\begin{array}{c}c_{21}=0 \\
c_{17}=c_{18}\end{array}$ \\
\hline $\begin{array}{l}\text { absorption chiller } \\
\text { absorber }\end{array}$ & $\begin{array}{c}c_{16} \dot{E} x_{16}+c_{20} \dot{E} x_{20}+c_{23} \dot{E} x_{23}+\dot{Z}_{a b s, A C H}=c_{11} \dot{E} x_{11}+c_{24} \dot{E} x_{24} \\
\frac{c_{16} \dot{E} x_{16}+c_{20} E x_{20}}{E x_{16}+\dot{E} x_{13}}=c_{11}\end{array}$ & $c_{23}=0$ \\
\hline $\begin{array}{l}\text { absorption chiller } \\
\text { evaporator }\end{array}$ & $c_{19} \dot{E} x_{19}+c_{25} \dot{E} x_{25}+\dot{Z}_{e v a, A C H}=c_{20} \dot{E} x_{20}+c_{26} \dot{E} x_{26}$ & $c_{19}=c_{20}$ \\
\hline
\end{tabular}

Table 4: Initial cost formula of the main component

\begin{tabular}{|c|c|}
\hline component & cost formula \\
\hline exchanger & $z_{\text {Cooler }, h x}=130\left(\frac{A_{\text {Cooler }, H X}}{0.093}\right)^{0.78}$ \\
\hline compressor & $z_{\text {gas }, \mathrm{com}}=71.1 \dot{m}_{\text {air }}\left(\frac{1}{0.9-\eta_{\text {gas }, \mathrm{com}}}\right)\left(\frac{p_{2}}{p_{1}}\right) \ln \left(\frac{p_{2}}{p_{1}}\right)$ \\
\hline combustion chamber & $\left(\frac{1}{0.995-\frac{p_{4}}{p_{3}}}\right) 48.08 \dot{m}_{\text {air }}\left(1+\exp \left(0.18 t_{2}-26.4\right)\right)$ \\
\hline gas turbine & $479.34 \dot{m}_{\text {gas }}\left(\frac{1}{0.92-\eta_{\text {gas }, \text { tur }}}\right) \ln \left(\frac{p_{3}}{p_{4}}\right)\left(1+\exp \left(0.036 t_{3}-54.4\right)\right.$ \\
\hline steam generator & $6570 \sum\left(\frac{\dot{q}_{i}}{\Delta T_{l m t d, i}}\right)^{0.8}+21276 \dot{m}_{7}+1184.4\left(\dot{m}_{\mathrm{gas}}\right)^{1.2}$ \\
\hline $\begin{array}{l}\text { heat exchangers in the } \\
\text { absorption cycle }\end{array}$ & $\begin{array}{l}z_{H X}=z_{R, H X}\left(\frac{A_{H X}}{A_{R, H X}}\right)^{0.6}, \text { reference area of the heat exchanger is } A_{R, H X}=100 \mathrm{~m}^{2} \\
z_{R, \text { gen }}=17500, z_{R, \text { con }}=8000, z_{R, \text { eva }}=16000, z_{R, a b}=16500 z_{R, \text { Shx }}=12000\end{array}$ \\
\hline pump & $z_{p}=z_{R, P}\left(\frac{\dot{w}_{p}}{\dot{w}_{R, p}}\right)^{0.26}\left(\frac{1-\eta_{p}}{\eta_{p}}\right)^{0.5}, \dot{w}_{R, P}=10 \mathrm{~kW}$ and $z_{R, P}=2100 \mathrm{USD}$ \\
\hline
\end{tabular}

The following equations calculate the general output work of the absorption chiller-equipped system (Config. 1) and compression chiller-equipped system (Config. 2):

$$
\begin{aligned}
& \dot{W}_{\text {net,Conf }, 1}=\dot{w}_{\text {gas }, t u r}-\dot{w}_{\text {air }, \text { com }} \\
& \dot{W}_{\text {net,Conf }, 2}=\dot{w}_{\text {gas }, \text { tur }}-\dot{w}_{\text {air }, \text { com }}-\dot{w}_{\text {com }, H P C}
\end{aligned}
$$

Eq. (3) is used to measure the energy efficiency of combined systems:

$\eta_{\text {en,net }}=\frac{\dot{W}_{\text {net }}+\dot{Q}_{H R S G}}{\dot{m}_{\text {fuel }} L H V_{\text {fuel }}}$

The energy efficiency is obtained from the following equations: 
$\eta_{\text {ex,conf }, 1}=\frac{\dot{W}_{\text {net,conf }, 1}+\dot{E} x_{8}-\dot{E} x_{7}}{E x_{f u e l}}$

$\eta_{\text {ex,conf }, 2}=\frac{\dot{W}_{\text {net,conf }, 2}+\dot{E} x_{7}-\dot{E} x_{6}}{E x_{f u e l}}$

In addition, the total cost rate is measured by Eq. 6 .

$\dot{C}_{\text {tot }}=\sum \dot{Z}_{k}+\sum \dot{C}_{\text {Dest }, k}$

The computation algorithm for simulation, analysis, and optimization has been shown in Figure 2. As demonstrated, each cycle's thermodynamic simulation has been performed in GT Pro and EES software.

Then, the economic calculation has been done in EES. After economic analysis, exergy and exergoeconomic analysis have been performed in EES. Then, sensitivity analysis has been carried out based on the main parameters. Due to reducing computation time of optimization, correlations for the prediction of objective function have been found by GMDH. Then, two-objective optimization has been performed by MOPSO.

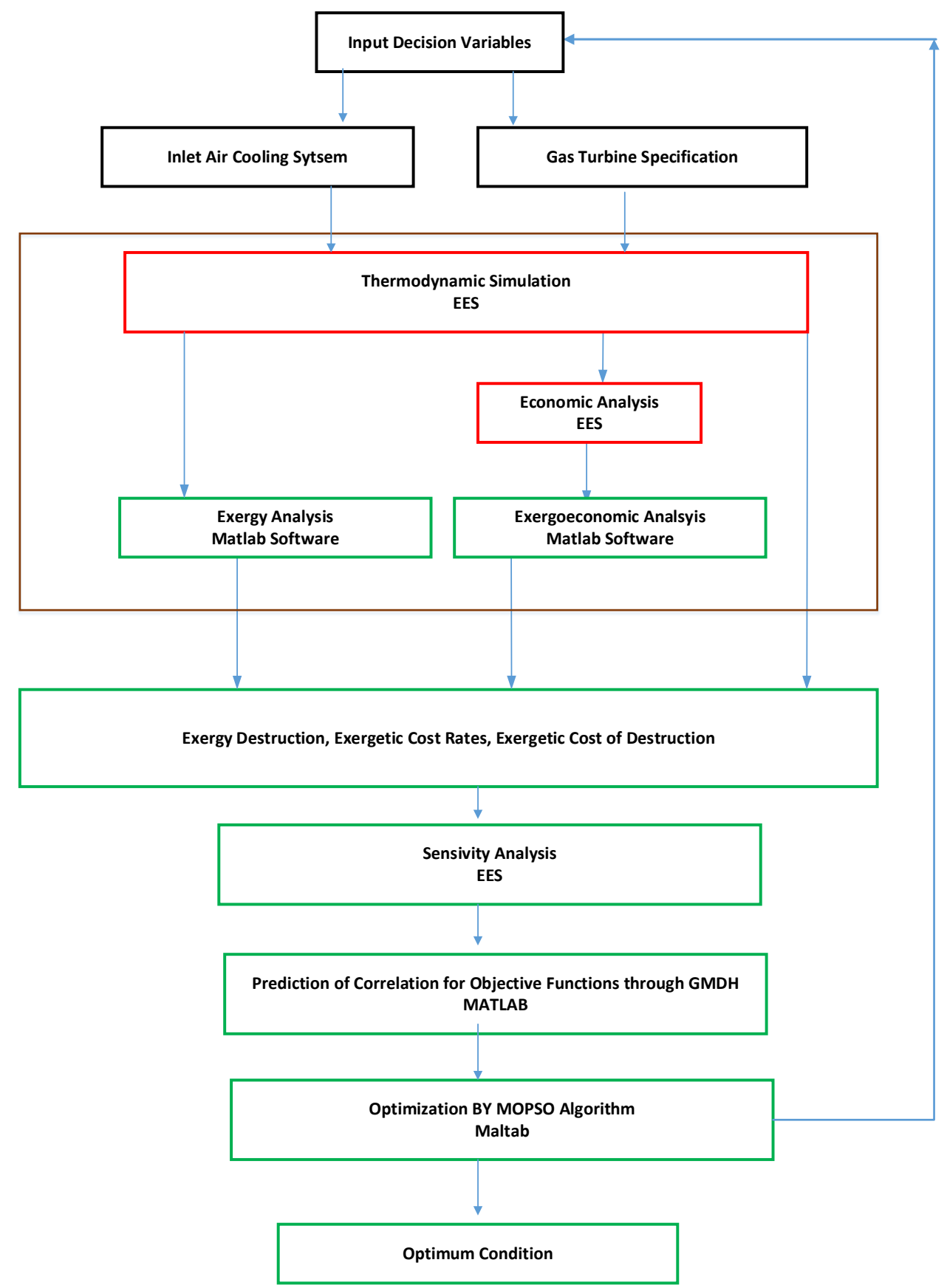

Figure 2. Computation Algorithm for simulation, analysis, and optimization

\section{Simulation and optimization Results}

The validation of thermodynamic simulation has been performed in GT PRO software. Table 3 shows the validation of simulation results of the combined system with an absorption chiller - Config. 1 with GT Pro software.
Also, Table 4 indicates the validation of simulation results performed by EES Code and GT Pro software. As shown in Table 3 and Table 4, simulation results have high accuracy. After validating the simulation results, this section presents the reference state output results to check the performance of the different components of the combined systems in 
question. Then, the parameters are analyzed to explore the effect of changing different factors on the systems' energy, exergy, and exergy-economic performance.

\subsection{Results of analysis}

Tables 5 and 6 present the output values for the energy rates and exergies of the combined system's various components. As can be seen, the highest exergy destruction happens in the combustion chamber, which is significantly greater than the other components. The gas turbine has the second-highest exergy destruction among the components of the combined system. Also, the highest exergy efficiency is related to the turbine and compressor in the gas cycle and the lowest to the cooling exchanger and absorption absorber. For the cogeneration system with an absorption chiller (Config. 1) at the reference input state, the total work is $41849 \mathrm{~kW}$, the total irreversibility is $64411 \mathrm{~kW}$, the exergy efficiency of power generation is 0.326 , and the exergy efficiency of cogeneration is 0.437 . The counterpart values are $38451 \mathrm{~kW}, 57760 \mathrm{~kW}, 0.3$, and 0.471 for the cogeneration system with a compression chiller (Config. 2). As is evident, the overall net power of Config. 1 is greater than that of Config. 2 because a part of the output work of
Config. 2 is consumed in the heat pump compressor (4130 $\mathrm{kW})$. On the other hand, the cogeneration's overall exergetic efficiency is higher in Config. 2 than in Config. 1. In Config. 2 , the gas turbine's heat output is only used to produce steam in the steam generator but in Config. 1 it is consumed by both the steam generator and the absorption generator so that, according to the tables, the heat generated in the steam generator is $59676 \mathrm{~kW}$ in Config. 2 and $38599 \mathrm{~kW}$ in Config. 1.

Finally, Tables 7 and 8 show the exergy-economic results for the combined systems. It is evident in the tables that the $\mathrm{CC}$ should be considered more from the exergy-economic perspective because this component has the highest value of $\dot{\mathrm{Z}}_{\mathrm{k}}+\dot{\mathrm{C}}_{\mathrm{D}, \mathrm{k}}$. Also, it can be observed that the CC, generator, condenser, and absorber have the lowest exergy-economic factor. The values obtained for these components imply that the cost of exergetic destruction prevails over the initial price, which reduces the exergy-economic factor. For such components in the cycle, it is recommended to increase the initial cost to minimize exergy destruction.

Table 5. The energy and exergy results for the combined system with an absorption chiller-Config. 1

\begin{tabular}{|c|c|c|c|c|}
\hline Component & $\dot{Q}$ or $\dot{W}(k W)$ & $\begin{array}{l}\text { \%Error Compare with } \\
\text { GT PRO Software }\end{array}$ & $\dot{E x_{\mathrm{D}}}(\boldsymbol{k} W)$ & $\eta_{e x}$ \\
\hline Chilling exchanger & 27211 & 1.23 & 842.3 & 0.262 \\
\hline Compressor & 66748 & 1.89 & 4883 & 0.926 \\
\hline Combustion chamber & - & & 34529 & 0.817 \\
\hline Gas turbine & 108597 & 1.83 & 7621 & 0.934 \\
\hline Steam generator & 38599 & 1.78 & 6354 & 0.691 \\
\hline Absorption generator & 35078 & 1.69 & 7244 & 0.411 \\
\hline Absorption condenser & 28908 & 1.22 & 585.9 & 0.43 \\
\hline Absorption evaporator & 27211 & 1.39 & 560.5 & 0.695 \\
\hline Absorption absorber & 33381 & 1.56 & 1452 & 0.2607 \\
\hline Solution heat exchanger & 5190 & 1.28 & 166.4 & 0.659 \\
\hline Solution pump & 0.285 & 1.33 & 0.274 & 0.04 \\
\hline Refrigerating pressure-reducing valve & - & 1.11 & 72.49 & 0.99 \\
\hline
\end{tabular}

Table 6. The energy and exergy results for the combined system with a compression chiller - Config. 2

\begin{tabular}{|c|c|c|c|c|}
\hline Component & $\dot{\boldsymbol{Q} o r \dot{W}(\boldsymbol{k W})}$ & $\begin{array}{c}\text { \%Error Compare with } \\
\text { GT PRO Software }\end{array}$ & $\boldsymbol{E x}_{\mathbf{D}}(\boldsymbol{k W})$ & $\boldsymbol{\eta}_{\boldsymbol{e x}}$ \\
\hline Chilling exchanger & 27211 & 1.39 & 1247 & 0.23 \\
\hline Compressor & 66748 & 1.87 & 4883 & 0.926 \\
\hline Combustion chamber & - & - & 34892 & 0.816 \\
\hline Gas turbine & 109330 & 1.73 & 7710 & 0.934 \\
\hline Steam generator & 59676 & 1.48 & 6655 & 0.767 \\
\hline Compression condenser & 31342 & 1.39 & 570 & 0.457 \\
\hline Compression evaporator & 27211 & 1.28 & 558.4 & 0.695 \\
\hline Compression compressor & 4130 & 1.47 & 875.3 & 0.809 \\
\hline Refrigerating pressure-reducing valve & - & - & 458.8 & 0.94 \\
\hline
\end{tabular}

This is accomplished in heat exchangers by increasing the heat exchanger area (which leads to an increase in its initial cost) and, on the other hand, by reducing the temperature difference in the heat exchanger (which results in an irreversible reduction in the heat exchanger). Among the components of the combined cycle, the performance of the solution pump has little effect on the exergy-economic performance of the process, as it has the lowest $\dot{\mathrm{Z}}_{\mathrm{k}}+\dot{\mathrm{C}}_{\mathrm{D}, \mathrm{k}}$ among all components.
Also, in Config. 1 the unit cost of electrical energy generated is $0.0646 \mathrm{USD} / \mathrm{kWh}$ in the gas turbine and $0.0884 \mathrm{USD} / \mathrm{kWh}$ in the steam generator, whilst these are 0.0633 and $0.0788 \mathrm{USD} / \mathrm{kWh}$ in Config. 2, respectively. As per the literature's recommendation, the unit exergy cost is an important parameter of the performance of energy conversion systems, so that its lower value in Config. 2 demonstrates the better performance of this Config. in this respect. 
Finally, the total amount of the exergy-economic factor is $9.315 \%$ in Config. 1 and $12.78 \%$ in Config. 2 . This figure indicates that $90.685 \%$ of the system cost in Config. 1 and $87.22 \%$ of the system cost in Config. 2 are related to the cost equivalent to the exergy destruction. As a result, the use of more expensive components, which will reduce the cost of exergy destruction and increase the initial cost of the system, will improve the exergy-economic parameters of the system. Also, the high-cost corresponding to the exergy destruction in both Configurations reveals the need for performing an exergy-economic analysis to find ways to decrease the exergy destruction cost.

To better understand the system's performance and the effect of different issues on the gas turbine cooling system's performance, this section first explores the effect of changing the inlet compressor temperature and the air temperature after cooling the heat exchanger on the gas turbine system. Then, the whole system's performance is examined, and the two systems in question are compared by changing the ratio of compressor pressure to the gas turbine's input temperature. In the parametric analysis, only the input parameter in question is changed, and other inputs are kept constant as per Table 1.
Figure 3 illustrates the impact of changing the hot inlet air temperature before the cooling phase in the heat exchanger in the range of $30-50^{\circ} \mathrm{C}$ on the gas turbine system's performance. It can be observed that the total output work of the gas turbine system decreases when the temperature of the inlet air of the system is increased, and the state of the output air of the cooling heat exchanger is kept constant (at $15^{\circ} \mathrm{C}$ and the saturation state). In this case, the increase in the inlet air temperature results in the reduction of the density and mass flow rate of the inlet air $\left(\dot{m}_{\text {air,in }}\right)$, leading to a decrease in the output air rate flowing out of the cooling exchanger $\left(\dot{m}_{\text {air }, \text { out }}\right)$ and the gas flow rate $\left(\dot{m}_{\text {gas }}\right)$. The outlet airflow rate from the cool exchanger is the same as the inlet air flow rate that has lost some of its humidity. The rate of gas flow is also the same as the rate of outlet airflow from the cool exchanger plus the rate of the flow of surplus fuel into the combustion chamber. As the temperature of the inlet air increases, if the enthalpy difference is constant in the compressor and gas turbine, the only factor that will influence the reduction of the work of the gas turbine system will be the reduction of the flow rate of the air and gas passing through the system.

Table 7. The exergoeconomic results for the combined system with an absorption chiller - Config. 1

\begin{tabular}{lllll}
\hline Component & $\dot{\boldsymbol{C}}_{\mathbf{D}}(\$ / \boldsymbol{h})$ & $\dot{\boldsymbol{Z}}(\$ / \boldsymbol{h})$ & $\dot{\boldsymbol{C}}_{\mathbf{D}}+\dot{\boldsymbol{Z}}(\mathbf{\$} / \boldsymbol{h})$ & $\boldsymbol{f}(\%)$ \\
\hline Chilling exchanger & 217.8 & 62.75 & 280.55 & 22.37 \\
Compressor & 315.8 & 195.8 & 511.6 & 38.28 \\
Combustion chamber & 1620 & 5.16 & 16.25 .16 & 0.31 \\
Gas turbine & 455 & 84.2 & 539.2 & 15.62 \\
Steam generator & 379.4 & 35.35 & 414.75 & 8.524 \\
Absorption generator & 432.5 & 3.818 & 436.318 & 0.875 \\
Absorption condenser & 93.5 & 0.25 & 93.75 & 0.26 \\
Absorption evaporator & 89.45 & 1.897 & 91.347 & 2.077 \\
Absorption absorber & 200.2 & 1.868 & 202.068 & 0.92 \\
Solution heat exchanger & 24.14 & 0.834 & 24.974 & 3.33 \\
Solution pump & 0.32 & 0.0036 & 0.3236 & 1.09 \\
Refrigerating pressure-reducing valve & 11.57 & - & 11.57 & - \\
\hline
\end{tabular}

Table 8. The exergoeconomic results for the combined system with a compression chiller - Config. 2

\begin{tabular}{lcclc}
\hline Component & $\dot{\boldsymbol{C}}_{\mathbf{D}}(\$ / \boldsymbol{h})$ & $\dot{\boldsymbol{Z}}(\mathbf{\$} / \boldsymbol{h})$ & $\dot{\boldsymbol{C}}_{\mathbf{D}}+\dot{\boldsymbol{Z}}(\mathbf{\$} / \boldsymbol{h})$ & $\boldsymbol{f}(\%)$ \\
\hline Chilling exchanger & 186.4 & 62.75 & 249.15 & 25.18 \\
Compressor & 309.4 & 195.8 & 505.2 & 38.76 \\
Combustion chamber & 1643 & 5.16 & 1648.16 & 0.31 \\
Gas turbine & 450.9 & 84.97 & 535.87 & 15.86 \\
Steam generator & 389.2 & 60.09 & 449.29 & 13.38 \\
Compression condenser & 45.57 & 5.915 & 51.486 & 11.49 \\
Compression evaporator & 44.64 & 44.09 & 88.73 & 49.69 \\
Compression compressor & 62.78 & 5.661 & 68.44 & 8.27 \\
Refrigerating pressure-reducing valve & 36.68 & - & 36.68 & - \\
\hline
\end{tabular}

Figure 4 shows the effect of the changes in the postcooling cool air temperature and humidity disposal on the heat exchanger in the range of $15-25^{\circ} \mathrm{C}$ on the gas turbine system's performance. As can be seen, the increase in the compressor inlet temperature is associated with decreased total system performance. In this case, with the volume flow rate and inlet air temperature to the cooling heat exchanger remaining constant, $\dot{m}_{\text {air }, \text { in }}$ remains constant, but further cooling of air beyond $15-25^{\circ} \mathrm{C}$ results in the further decline of humidity so that the lowest outlet air flow rate $\dot{m}_{\text {air,out }}$ and gas flow rate $\dot{m}_{\text {gas }}$ are obtained at $15^{\circ} \mathrm{C}$. But here, unlike a higher flow rate at $25^{\circ} \mathrm{C}$, the output work is reduced. As the temperature increases from 15 to $25^{\circ} \mathrm{C}$, the two factors of flow rate passing through the compressor and turbine and the enthalpy difference in the turbine are increased, resulting in a higher work in the compressor and turbine. However, the extent to which the compressor's work requirement increases exceeds the increase in the output work of the turbine, resulting in the loss of the total output work of the system. It can be inferred from these two recent parametric analyses that the decrease in the air temperature both in the input and output of the cooling heat exchanger will increase the net output work of the gas turbine system.

Figure 5 indicates the effect of the variation in the compressor pressure ratio on the studied systems' energy and exergy performance. As can be seen, both systems' overall output work has a maximum value at a pressure ratio of about 8 . The increase in the pressure ratio 
increases the compressor work requirement and turbine output work. Initially, the increase in turbine output work is greater, leading to an increase in the overall output work, but beyond the pressure ratio of 8 , the increase in the compressor work requirement is greater, resulting in a decrease in the overall output work. The overall output work of Config. 2 is less than that of Config. 1 throughout the studied range because a part of the turbine work in the former is spent on supplying the work requirement of the compression chiller compressor. On the other hand, as shown in the figure, the exergy efficiency of Config. 2 is greater than that of Config. 1. In Config. 2, the gas turbine's waste exhaust gas is only used to generate heat in the steam generator, but in Config. 1, the waste gas is consumed in both the steam generator and the absorption

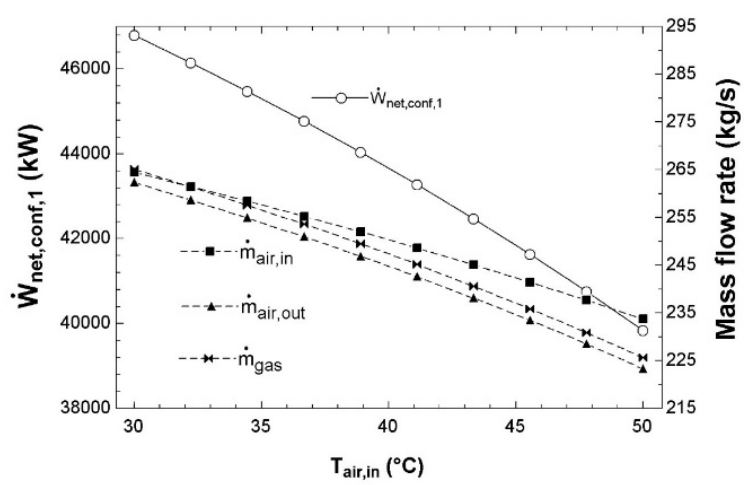

Figure 3. The impact of the variation in inlet air temperature on the net power of the gas turbine

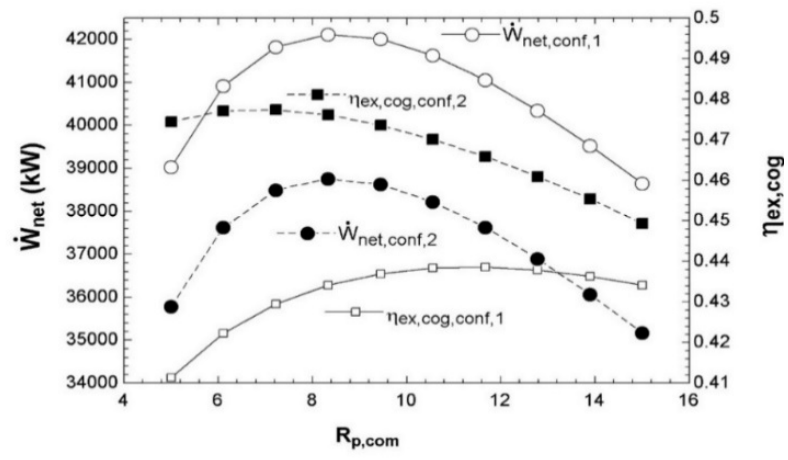

Figure 5. The effect of the variation in compressor pressure ratio on the energy and exergy analyses of the systems

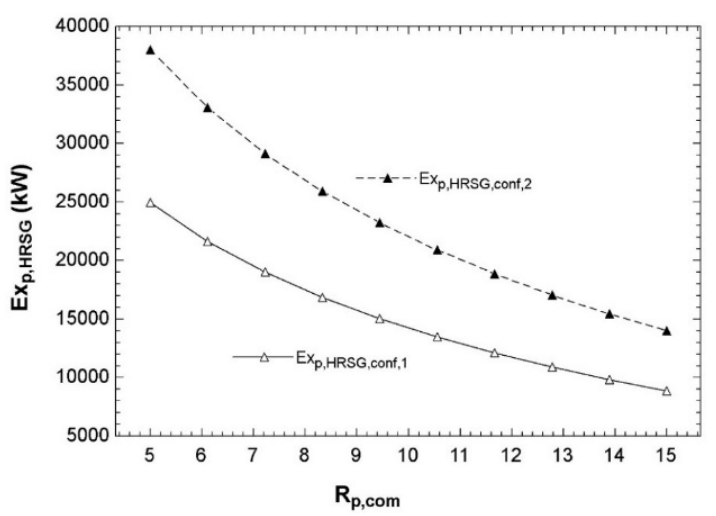

Figure 7. The effect of the variation in compressor pressure ratio on the product exergy of the heat exchanger generator. The high heat generation of Config. 2 increases the exergy efficiency of Config. 2 versus Config. 1. On the other hand, according to the figure, the trend of exergy efficiency variations in Config. 1 is incremental, mainly due to the decrease in fuel flow rate requirement and fuel exergy of the chamber with a relative increase in the compressor pressure as per Figure 6. However, in Config. 2 , despite the decrease in fuel requirement, the reduction of the heat exchanger product's exergy, as shown in Figure 7 causes a more pronounced decrease in the exergy efficiency. It is evident in Figure 7 that the reducing trend of the exergy of the steam generator product in Config. 2 is more severe than that of Config. 1, which has a more pronounced effect on the reducing trend of the exergy in Config. 2.

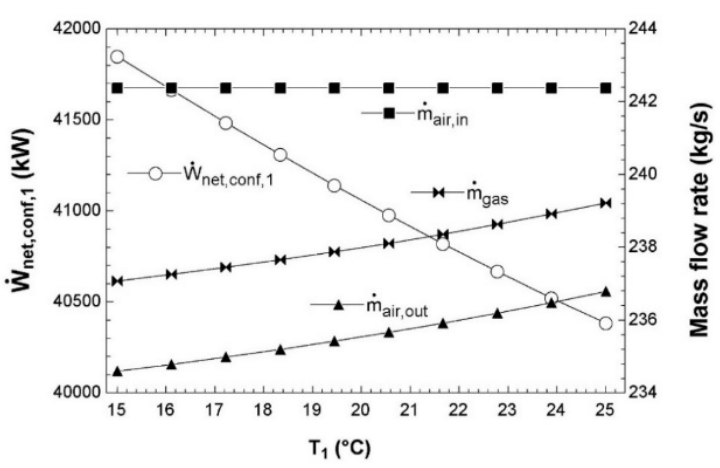

Figure 4. The impact of the variation in inlet compressor temperature on the net power of the gas turbine

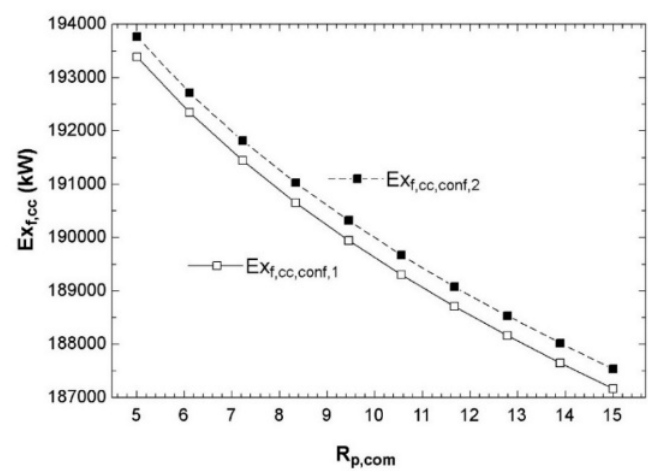

Figure 6. The effect of the compressor pressure ratio on the exergy of the combustion chamber's fuel

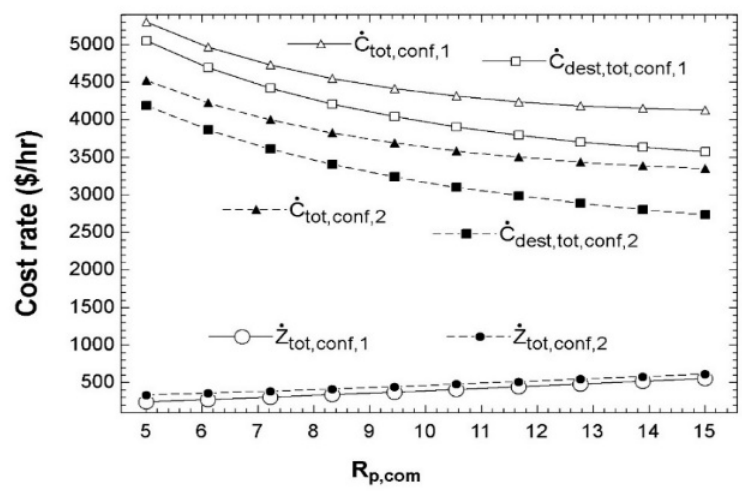

Figure 8. The effect of the variation in compressor pressure ratio on the cost rates 


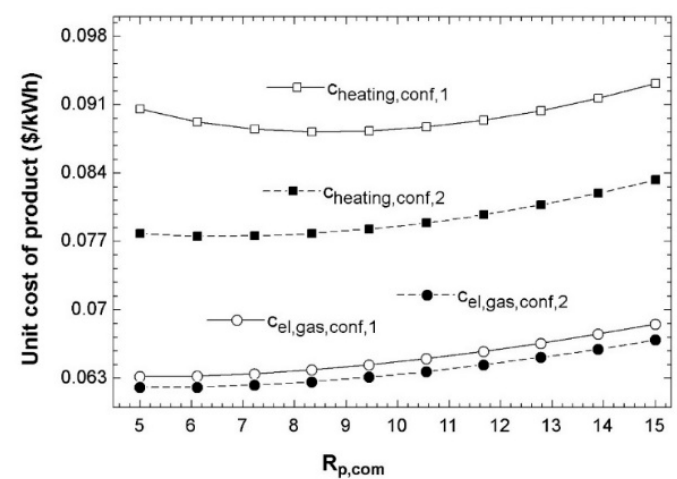

Figure 9. The effect of the variation in compressor pressure ratio on the unit exergy cost of the products

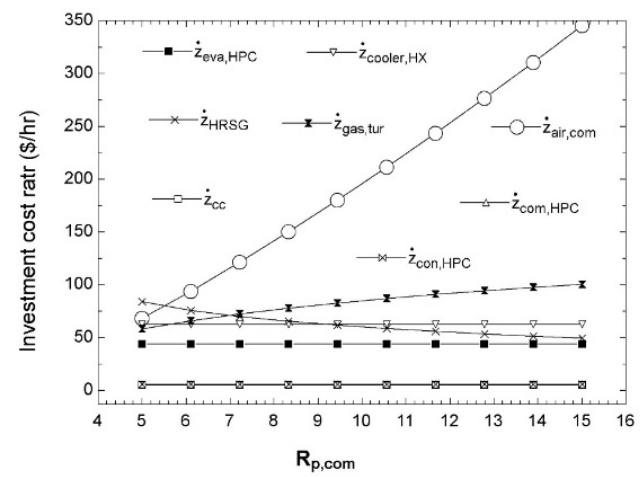

Figure 11. The effect of the variation in compressor pressure ratio on the initial cost rate of different Config components. 1

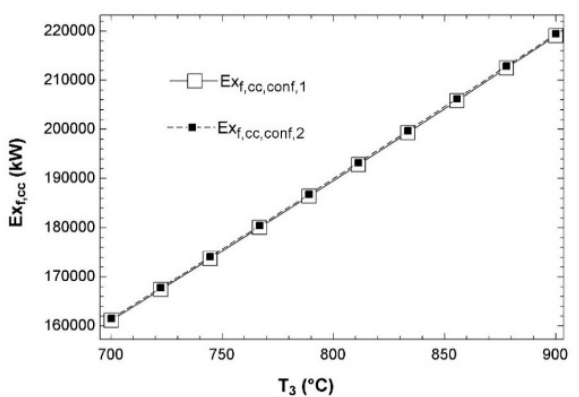

Figure 13. The effect of the variation in the gas turbine inlet temperature on the fuel exergy of the combustion chamber

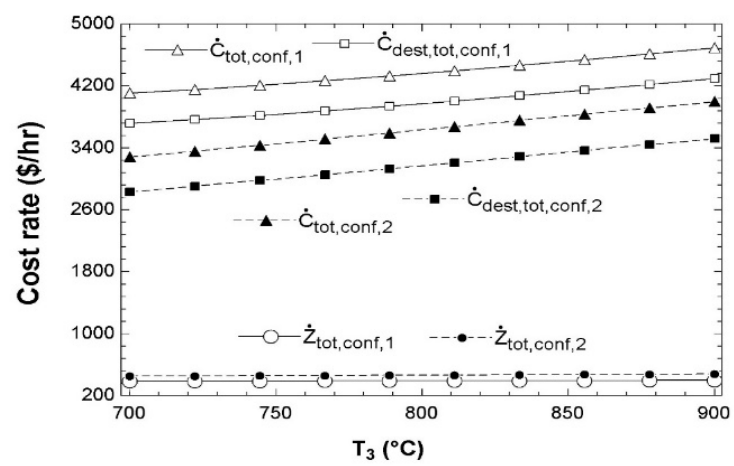

Figure 15. The effects of the variation in the inlet temperature of the turbine on the cost rates

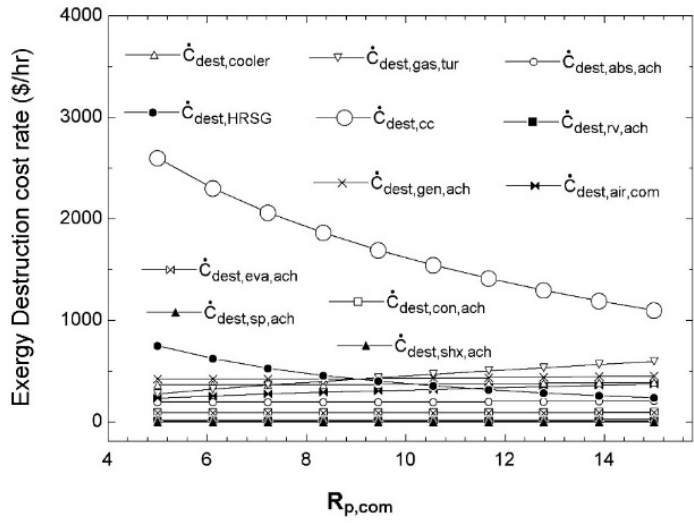

Figure 10. The effect of the variation in compressor pressure ratio on the exergy destruction cost of different components in Config. 1

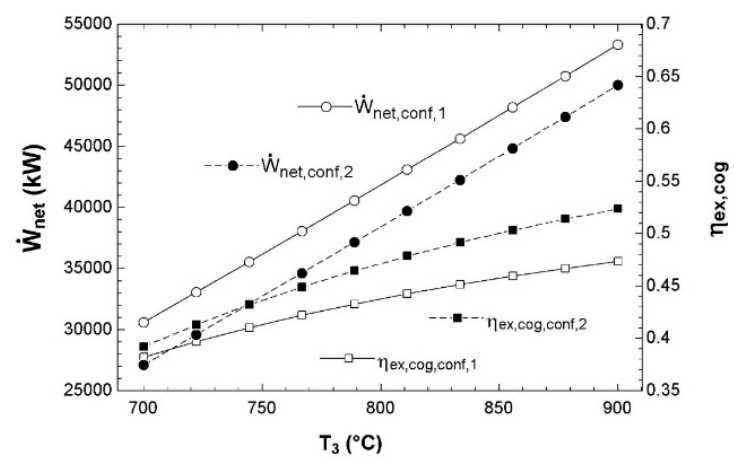

Figure 12. The effect of the variation in the gas turbine inlet temperature of the energy and exergy analyses of the systems

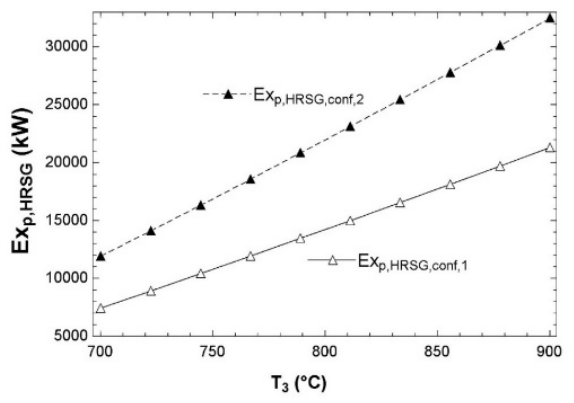

Figure 14. The effect of the variation in the inlet temperature of the gas turbine on the product exergy of the steam generator

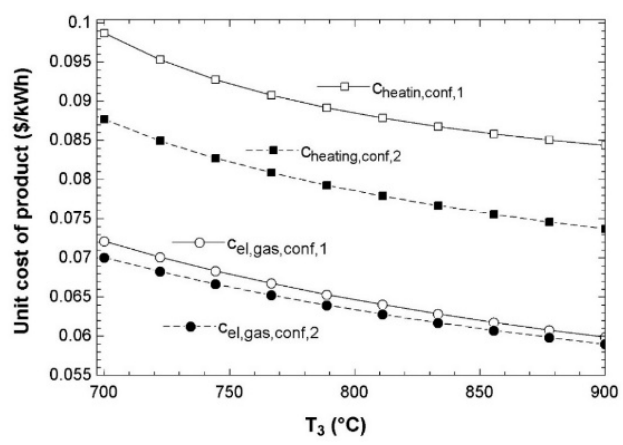

Figure 16. The effects of the variation in the inlet temperature of the turbine on the exergy unit cost of the products 


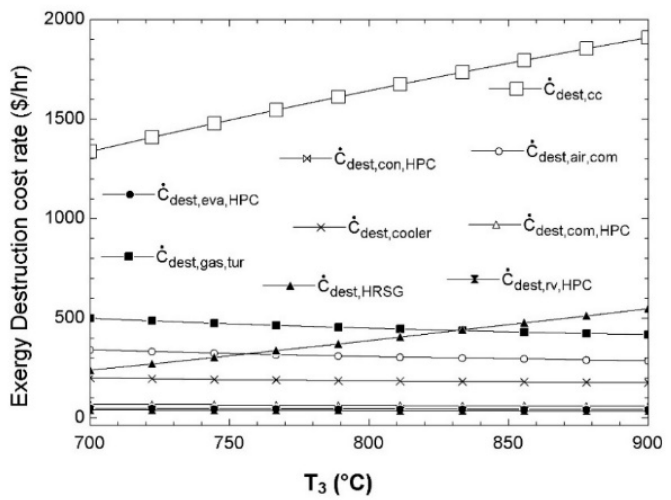

Figure 17. The effects of the variations in the turbine inlet temperature on the exergy destruction cost rate of different components in Config. 2

Figures 8 and 9 show the effect of the compressor pressure ratio changes on the thermo-economic parameters of the systems in question. However, as shown in Figure 9, a rise in the compressor pressure ratio causes an increase in the initial cost rate and a decrease in the cost of exergy destruction. Figure 10 shows the effect of changing the compressor pressure ratio on the exergy destruction cost in Config. 1. As determined in Figure 11, the increase in compressor cost is the deciding factor in the increase in the total initial cost rate. Also, as shown in Figure 9, Config. 1 has a higher exergy unit cost of electricity and heat generation than Config. 2 over the studied range.

It can be observed in Figure 12 that increasing the inlet temperature of the gas turbine increases the total net power and exergy efficiency of the cogeneration in both systems. In Config. 2, a part of the turbine's output work is spent on the input work of the compressor. Consequently, the output work of this Config. is lessened. In the denominator of the exergy efficiency fraction, despite the increase in fuel flow rate and the equivalent exergy according to Figure 13, the increase in the output work and the exergy of the steam generator product as per Figure 14 results in an increase in the exergy efficient of the cogeneration system in both Config.s. Due to the higher product exergy of the steam generation in Config. 2 (Figure 14), this Config. has higher exergy efficiency than Config. 1.

Figures 15 and 16 show the effects of inlet temperature change in the gas turbine on the studied systems' thermoeconomic performance. It can be observed in Figure 15 that an increase in the inlet temperature of the turbine increases the initial cost rate slightly. Still, the exergy destruction cost rate increases significantly in both systems, resulting in a higher total cost rate. The total cost rate in Config. 1 is also higher than that in Config. 2 over the whole studied range. Here, the effect of the change in

Table 9. Constants of the relationship predicted by GMDH for the function of exergetic efficiency and total exergetic cost rate in Config. 1

\begin{tabular}{cccccccc}
\hline target & $\mathbf{a}(\mathbf{i}, \mathbf{j})$ & $\mathbf{j}=\mathbf{1}$ & $\mathbf{j}=\mathbf{2}$ & $\mathbf{j}=\mathbf{3}$ & $\mathbf{j}=\mathbf{4}$ & $\mathbf{j}=\mathbf{5}$ & $\mathbf{j}=\mathbf{6}$ \\
\hline exergy efficiency & $\mathrm{i}=1$ & -0.45533 & -0.01531 & 0.00194 & -0.00059 & $-1.14 \mathrm{E}-06$ & $3.54 \mathrm{E}-05$ \\
total cost rate & $\mathrm{i}=1$ & 4343.121 & -196.147 & 0.458243 & 14.45139 & $3.19 \mathrm{E}-03$ & $-2.54 \mathrm{E}-01$ \\
\hline
\end{tabular}

Table 10. Constants of the relationship predicted by GMDH for the function of exergetic efficiency and total exergetic cost rate in Config. 2

\begin{tabular}{cccccccc}
\hline target & $\mathbf{a}(\mathbf{i}, \mathbf{j})$ & $\mathbf{j}=\mathbf{1}$ & $\mathbf{j}=\mathbf{2}$ & $\mathbf{j}=\mathbf{3}$ & $\mathbf{j}=\mathbf{4}$ & $\mathbf{j}=\mathbf{5}$ & $\mathbf{j}=\mathbf{6}$ \\
\hline exergy efficiency & $\mathrm{i}=1$ & -0.6328 & -0.031 & 0.002525 & -0.00046 & $-1.45 \mathrm{E}-06$ & $4.58 \mathrm{E}-05$ \\
total cost rate & $\mathrm{i}=1$ & 2082.983 & -260.341 & 5.03056 & 12.34483 & $-2.03 \mathrm{E}-04$ & $-1.22 \mathrm{E}-01$ \\
\hline
\end{tabular}




\subsection{Results of optimization by MOPSO}

The optimization problem and the ranges of the design variables are as below. It can be seen that the problem has no constraints and only the ranges of the variables $x_{1}$ and $x_{2}$, which are equivalent to pressure and temperature, respectively, should be satisfied.

Minimize $\dot{C}\left(x_{1}, x_{2},\right)$ and Maximize $\eta_{e x}\left(x_{1}, x_{2},\right)$ subject to : $5 \leq x_{1}=r_{5} \leq 15,700^{\circ} \mathrm{C} \leq x_{2}=$ TIT $\leq$ $900{ }^{\circ} \mathrm{C}$
The optimization results are obtained from the algorithm for a particle population of 200 and the parameters presented in Table 11. The Pareto curve is shown in Figure 19 for System 1 and in Figure 20 for System 2. In order to have more continuous points on the Pareto curve, the archive size is set at 100 .

Table 11. The parameters of the MOPSO algorithm in determining the Pareto curve

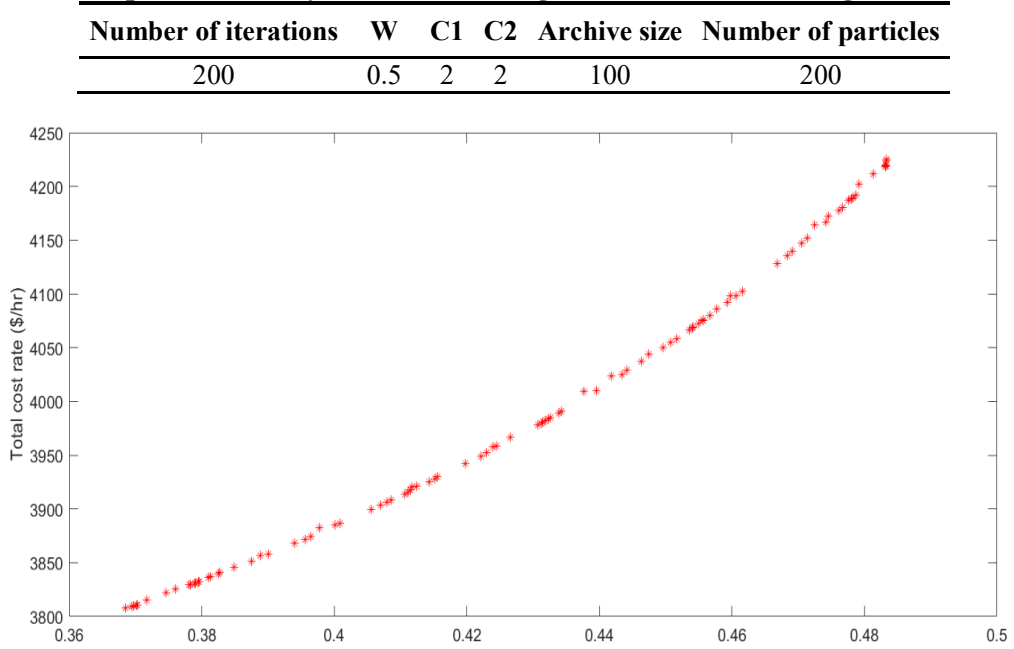

Figure 19. The exergetic and total exergetic cost rate optimization of System 1

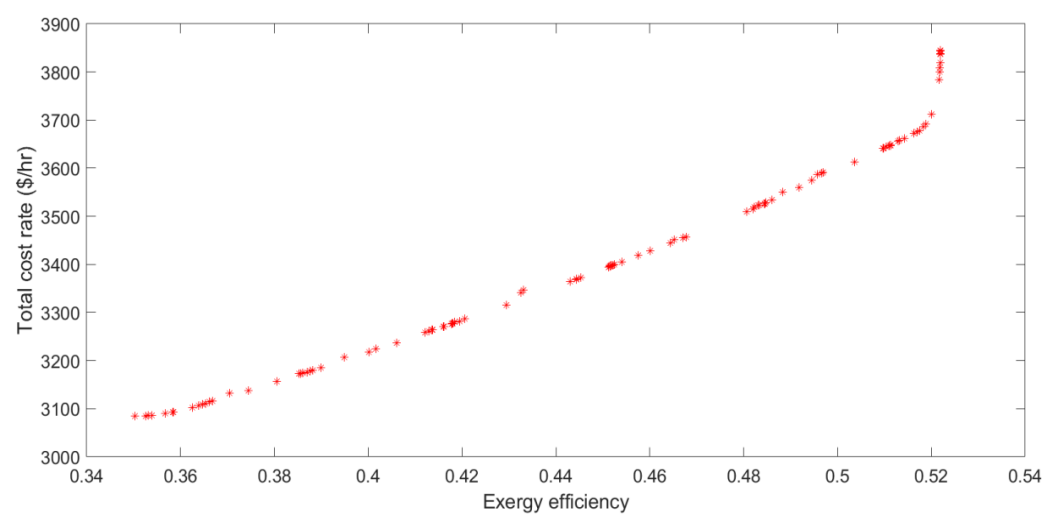

Figure 20. The exergetic and total exergetic cost rate optimization of System 1

As shown in Figures 19, 20, as the exergetic efficiency increases, the exergetic cost rate increases as well, indicating a contradictory behavior of these two objective functions. The Pareto curve gives the designer a useful tool to select the appropriate design according to each objective's importance.

The minimum total cost rate and the maximum exergy can be derived from the Pareto curve's points corresponding to the Pareto answer. To determining the compromise answer, the data in the objective functions column were first normalized versus their best values. Then the answer with the lower distance to the mean 0.5 line was selected. The compromise point is shown in Figure 21 for System
1 and in Figure 22 for System 2. These three types of answers are summarized in Table 12 for System 1 and in Table 13 for System 2. According to the results, when the compressor inlet temperature is raised, and the cooling heat exchanger's outlet air is constant, the gas turbine system's total net power decreases, indicating that rising the inlet compressor temperature drops the mass flow rate and density of the inlet air. In the cool exchanger, the reduction of post-cooling cool air temperature and the reduction of humidity in the range of $15-25^{\circ} \mathrm{C}$ implies that the rise in the in compressor inlet temperature in this range results in the reduction of the total work of the system. 


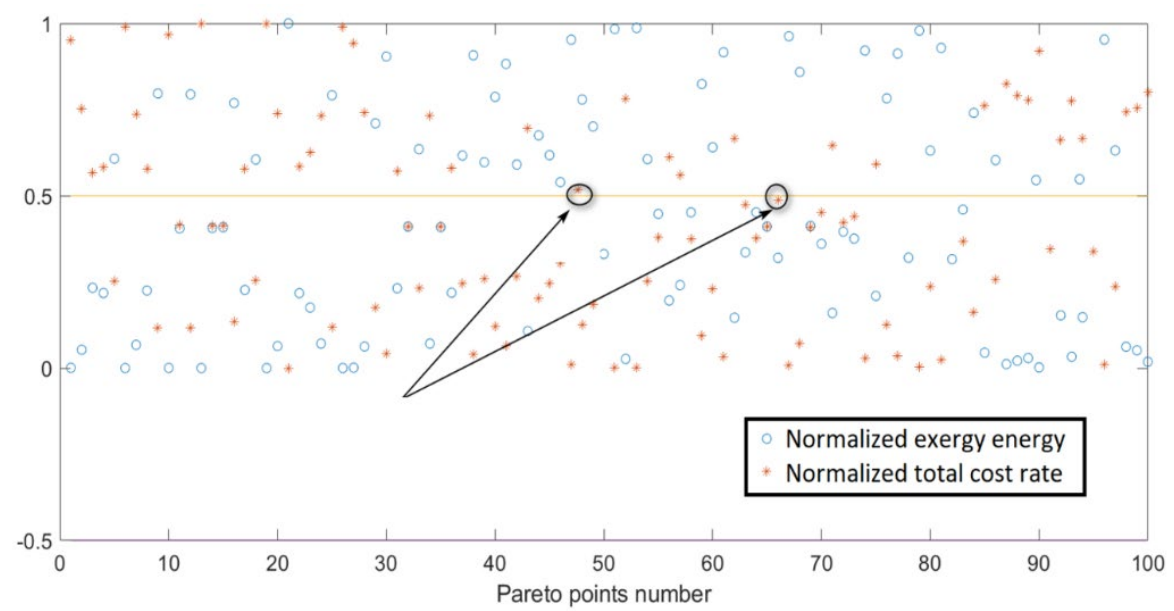

Figure 21. The normalized values for the objective functions in the Pareto answers in System 1

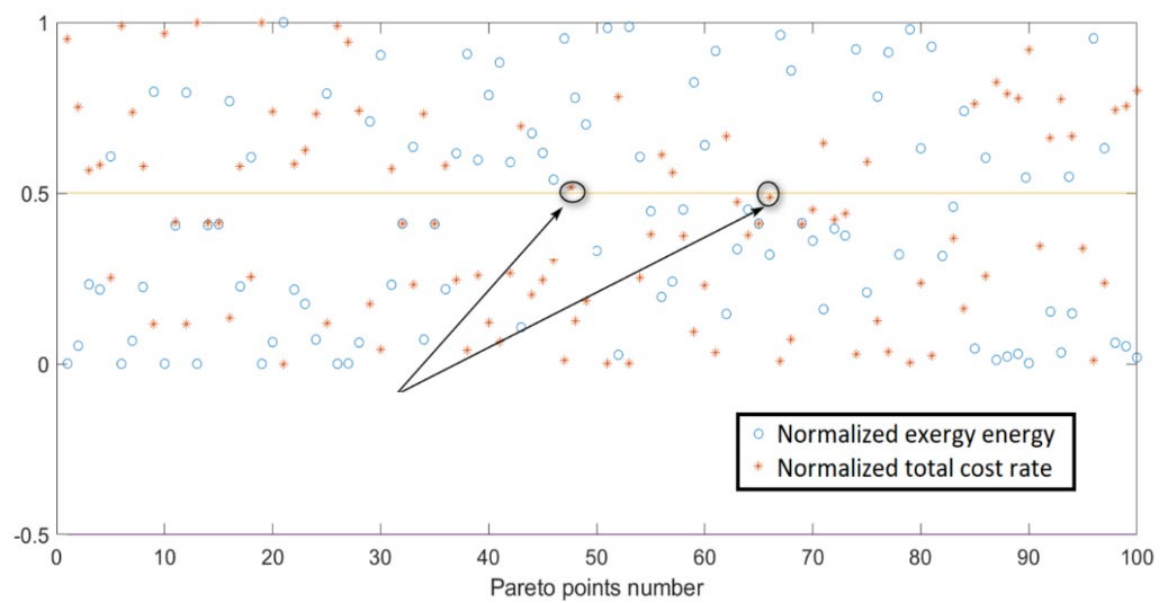

Figure 22. The normalized values for the objective functions in the Pareto answers in System 2

Table 12. Three sample points of the optimization results using the particle swarm algorithm in System 1

\begin{tabular}{ccccc}
\hline & $\boldsymbol{r}_{\boldsymbol{p}}$ & $\boldsymbol{T I T}$ & Exergy efficiency & Total cost rate (USD/h) \\
\hline Upper right-hand side point & 14.02787 & 900 & 0.483 & 4224.90 \\
Compromise points & 13.6100 & 808.02 & 0.439 & 4010.2 \\
& 12.8248 & 801.32 & 0.437 & 4009.8 \\
Lower left-hand side point & 12.82032 & 700 & 0.368 & 3808.11 \\
\hline
\end{tabular}

Table 13. Three sample points of the optimization results using the particle swarm algorithm in System 2

\begin{tabular}{ccccc}
\hline & $\boldsymbol{r}_{\boldsymbol{p}}$ & $\boldsymbol{T I T}$ & Exergy efficiency & Total cost rate (USD/h) \\
\hline Upper right-hand side point & 11.24823 & 900 & 0.5219 & 3844.52 \\
Compromise points & 13.8500 & 822.33 & 0.4671 & 3455.3 \\
& 13.6017 & 793.35 & 0.4452 & 3372.5 \\
Lower left-hand side point & 13.87814 & 700 & 0.3503 & 3084.31 \\
\hline
\end{tabular}

Also, when the volumetric flow rate and inlet air temperature of the cool exchanger is constant, the flow rate of the inlet air to the cooling heat exchanger will be constant, but further cooling of air beyond $15-25^{\circ} \mathrm{C}$ will increase the humidity, resulting in the lowest rate of outlet air from the cooling heat exchanger and the flow rate of gas at $15^{\circ} \mathrm{C}$.

In other words, it can be said that in the range of $15-25^{\circ} \mathrm{C}$, the work of the compressor increases, and this results in the decline of total output work of the system.

The comparison of the results for the total work of the combined system shows that the cogeneration system with an absorption chiller (Config. 1) is higher while the total output work of the cogeneration system with the compression chiller (Config. 2) is higher. This difference is partial because the output work of Config. 2 is consumed by the compressor of the heat pump, resulting in the reduction of the system's net power.
On the other hand, the combined system's exergoeconomic analysis implies that the consumption chamber needs to be explored more than the other components from the exergoeconomic perspective. Also, it is evident in Tables 10 and 11 that the combustion chamber, generator, condenser, and absorber have the lowest exergoeconomic factor. Based on the results, the exergy destruction cost dominates the initial cost, and this reduces the exergy-economic factor.

It is noteworthy that the total exergoeconomic factor is $9.315 \%$ in Config. 1 and $12.78 \%$ in Config. 2. This means that $90.685 \%$ of the system cost in Config. 1 and $87.22 \%$ in Config. 2 are due to the cost equivalent to the exergy destruction. So, the application of components with a higher price that reduces the exergy destruction cost and increases the system's initial cost can improve the system's exergoeconomic performance. In both studied Configurations, the highest cost of exergy destruction means 
that it is necessary to find approaches to reducing this cost. Another point to note is that the significantly higher cost rate of the exergy destruction than the initial cost rate in both systems is why it is necessary to conduct an exergoeconomic analysis to calculate the thermodynamic inefficiencies' cost rate. The compressor pressure ratio's increase has a complicated and contradictory impact on different components' cost rates. Based on the results, the compressor cost increase is a decisive factor in increasing the initial cost's total rate. It can be seen that an increase in the inlet temperature of the gas turbine escalates the total output work and exergy efficiency of cogeneration in both systems. In this case, increasing the inlet temperature of the turbine and the combustion chamber's output temperature under a constant work requirement of the compressor will increase the enthalpy difference in the turbine and the required flow rate of the inlet fuel and the mix of outlet gases of the chamber. These two factors will both enhance the output work of the gas turbine. In Config. 2, the turbine's output work is in part consumed for the input work of the compressor, and this reduces the output work of the Configuration.

The optimization by the research can be used to select the best design by considering the objective functions. According to the solutions, the minimum total exergetic cost rate and the maximum exergetic efficiency obtained, and the solutions in which both objective functions show acceptable behavior are introduced as per Tables 7 and 8 .

\section{Conclusion}

The present paper investigates cooling air inlet methods on gas turbine compressors to enhance their efficiency. Two inlet air cooling systems include absorption and compression systems, have been considered. In the absorption system, lithium bromide-water conventional solution is applied as a two-component fluid, and in the compression cycle, the $\mathrm{R} 134 \mathrm{a}$ operating fluid is considered.

All cycles have been simulated in the EES software and verified by GT Pro Software with high accuracy. In addition, to better analysis, exergy and exergoeconomic analysis of each component of cycles have been investigated. Also, sensitivity analysis has been performed for the main parameters of the cycles. To finding optimum design parameters of each cycle, two-objective optimization has been performed based on minimizing total exergetic costs and maximize exergetic efficiency.

To reduce optimization computation time, GMDH has been employed to generate correlations for predicting objective functions based on decision variables. The correlation for estimation of objective functions has good accuracy. Then, these objective functions have been used in MATLAB software for multi-objective optimization through MOPSO. In future research, environmental consideration and exergoenvironmental analysis can be investigated. In addition, using the different cooling systems in the combined cycle power plant can be considered. Also, reliability and risk assessment of using different air inlet cooling systems for gas turbines can be performed.

\section{Nomenclature}

$\begin{array}{lc}\text { Absorber temperature } & t_{\mathrm{abs}}\left({ }^{\circ} \mathrm{C}\right) \\ \text { Absorption generator temperature } & t_{\mathrm{gen}}\left({ }^{\circ} \mathrm{C}\right) \\ \text { Absorption and compression condenser } & t_{\mathrm{con}}\left({ }^{\circ} \mathrm{C}\right) \\ \text { temperature } & \dot{Q} \\ \text { Amount of heat transfer } & \dot{Q}\end{array}$

Average cost of fuel unit

Absorption and compression evaporator temperature

Absorption solution pump efficiency

Absorption solution heat exchanger

efficiency

Average cost of production unit

Capital return factor

Capital profit rate

Coefficient of performance and

maintenance cost

Config.

Cost equivalent to exergy destruction

Cost of exergy unit

Cost rate for a component

Exergy-economic factor

Exergy efficiency

Exergy destruction rate

Exergy rate equivalent to work transfer

Exergy rate equivalent to heat transfer

Flow exergy rate

Inlet air volume flow rate

Inlet air temperature

Inlet air pressure

Inlet air relative humidity

Inlet water temperature of steam

generator

Inlet water pressure of steam generator

Input air of gas turbine temperature

Isentropic efficiency

Number of hours of annual performance of components

Number of years of system performance

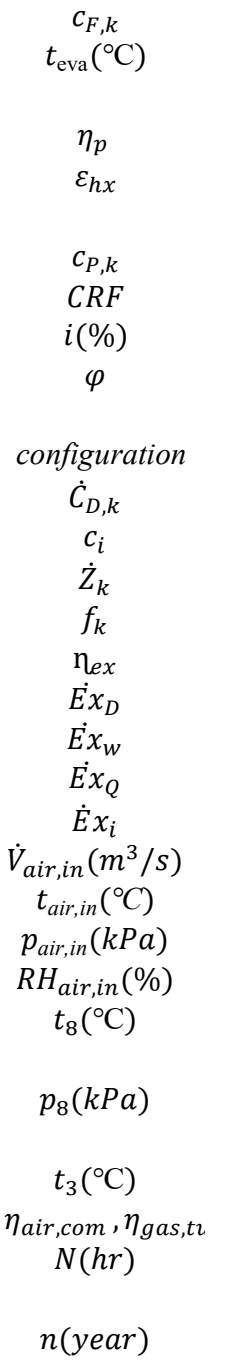

Lower thermal value of fuel

Partial pressure of dry air

Pressure ratio

Pressure of input fuel of combustion

chamber

Pressure ratio of air compressor

Temperature of inlet cool water of

condenser and absorber

Temperature of outlet cool water of

condenser and absorber

Temperature of inlet cool water of

evaporator

Temperature of outlet cool water of

evaporator

Temperature of input fuel of combustion

chamber

Volumetric flow rate

$$
\begin{gathered}
L H V(k J / k m o l) \\
P_{\text {dryair,air }, \text { in }} \\
r_{p} \\
P_{\text {fuel }}(k P a) \\
r_{p, \text { air,com }} \\
t_{\mathrm{cw}, \text { in }}\left({ }^{\circ} \mathrm{C}\right) \\
t_{\mathrm{cw}, \text { out }}\left({ }^{\circ} \mathrm{C}\right) \\
t_{\text {chw,in }}\left({ }^{\circ} \mathrm{C}\right) \\
t_{\text {chw }, \text { out }}\left({ }^{\circ} \mathrm{C}\right) \\
t_{\text {fuel }}\left({ }^{\circ} \mathrm{C}\right) \\
\dot{m}
\end{gathered}
$$

\section{References}

[1] C. M. Bartolini and D. Salvi, "Performance assessment of steam injection gas turbine with inlet air cooling," in ASME 1997 International Gas Turbine and Aeroengine Congress and Exhibition, 1997, p. V003T10A014-V003T10A014.

[2] A. M. Bassily, "Performance improvements of the intercooled reheat regenerative gas turbine cycles using indirect evaporative cooling of the inlet air and evaporative cooling of the compressor discharge," Proc. Inst. Mech. Eng. Part A J. Power Energy, vol. 
215, no. 5, pp. 545-557, 2001.

[3] A. M. Bassily, "Effects of evaporative inlet and aftercooling on the recuperated gas turbine cycle," Appl. Therm. Eng., vol. 21, no. 18, pp. 1875-1890, 2001.

[4] M. A. Chaker, C. B. Meher-Homji, and T. Mee III, "Inlet fogging of gas turbine engines: experimental and analytical investigations on impaction pin fog nozzle behavior," J. Eng. Gas Turbines Power, vol. 128, no. 4, pp. 826-839, 2006.

[5] R. Hosseini, A. Beshkani, and M. Soltani, "Performance improvement of gas turbines of Fars (Iran) combined cycle power plant by intake air cooling using a media evaporative cooler," Energy Convers. Manag., vol. 48, no. 4, pp. 1055-1064, 2007.

[6] M. De Lucia, E. Carnevale, M. Falchetti, and A. Tesei, "Performance improvements of a natural gas injection station using gas turbine inlet air cooling," 1997.

[7] M. De Lucia, C. Lanfranchi, and V. Boggio, "Benefits of compressor inlet air cooling for gas turbine cogeneration plants," 1996.

[8] M. M. Alhazmy and Y. S. H. Najjar, "Augmentation of gas turbine performance using air coolers," Appl. Therm. Eng., vol. 24, no. 2-3, pp. 415-429, 2004.

[9] S. Boonnasa, P. Namprakai, and T. Muangnapoh, "Performance improvement of the combined cycle power plant by intake air cooling using an absorption chiller," Energy, vol. 31, no. 12, pp. 2036-2046, 2006.

[10] M. Ameri and S. H. Hejazi, "The study of capacity enhancement of the Chabahar gas turbine installation using an absorption chiller," Appl. Therm. Eng., vol. 24, no. 1, pp. 59-68, 2004.

[11] F. Behafarid and M. N. Bahadori, "Performance Evaluation of a Gas Turbine Operating Noncontinuously with its Inlet Air Cooled Through an Aquifer Thermal Energy Storage," J. Energy Resour. Technol., vol. 129, no. 2, pp. 117-124, Dec. 2006, doi: 10.1115/1.2719203.

[12] B. Dawoud, Y. H. Zurigat, and J. Bortmany, "Thermodynamic assessment of power requirements and impact of different gas-turbine inlet air cooling techniques at two different locations in Oman," Appl. Therm. Eng., vol. 25, no. 11-12, pp. 1579-1598, 2005.

[13] M. Farzaneh-Gord and M. Deymi-Dashtebayaz, "Effect of various inlet air cooling methods on gas turbine performance," Energy, vol. 36, no. 2, pp. 1196-1205, 2011.

[14] S. Sanaye, M. Amani, and P. Amani, "4E modeling and multi-criteria optimization of CCHPW gas turbine plant with inlet air cooling and steam injection," Sustain. Energy Technol. Assessments, vol. 29, pp. 70-81, 2018.

[15] A. Baghernejad, M. Yaghoubi, and K. Jafarpur, "Exergoeconomic optimization and environmental analysis of a novel solar-trigeneration system for heating, cooling and power production purpose," Sol. Energy, vol. 134, pp. 165-179, 2016.

[16] Y. L. Liu and R. Z. Wang, "Performance prediction of a solar/gas driving double effect $\mathrm{LiBr}-\mathrm{H} 2 \mathrm{O}$ absorption system," Renew. Energy, vol. 29, no. 10, pp. 1677-1695, 2004.
[17] W. F. Malewski and G. M. Holldorff, "Power Increase of Gas Turbines by Inlet Air Pre-Cooling with Absorption Refrigeration Utilizing Exhaust Waste Heat," in ASME 1986 International Gas Turbine Conference and Exhibit, 1986, p. V003T07A006-V003T07A006.

[18] S. Sanaye, A. Fardad, and M. Mostakhdemi, "Thermoeconomic optimization of an ice thermal storage system for gas turbine inlet cooling," Energy, vol. 36, no. 2, pp. 1057-1067, 2011.

[19] A. Toffolo and A. Lazzaretto, "Evolutionary algorithms for multi-objective energetic and economic optimization in thermal system design," Energy, vol. 27, no. 6, pp. 549-567, 2002.

[20] A. Lazzaretto and A. Toffolo, "Energy, economy and environment as objectives in multi-criterion optimization of thermal systems design," Energy, vol. 29, no. 8, pp. 1139-1157, 2004.

[21] S. M. Seyyedi, H. Ajam, and S. Farahat, "A new approach for optimization of thermal power plant based on the exergoeconomic analysis and structural optimization method: Application to the CGAM problem," Energy Convers. Manag., vol. 51, no. 11, pp. 2202-2211, 2010.

[22] T. K. Ibrahim and M. M. Rahman, "Optimum Performance Improvements of the Combined Cycle Based on an Intercooler-Reheated Gas Turbine," $J$. Energy Resour. Technol., vol. 137, no. 6, Nov. 2015, doi: $10.1115 / 1.4030447$.

[23] A. Khaliq, M. A. Habib, and K. Choudhary, "A Thermo-Environmental Evaluation of a Modified Combustion Gas Turbine Plant," J. Energy Resour. Technol., vol. 141, no. 4, Nov. 2018, doi: 10.1115/1.4041898.

[24] A. Abdel Rahman and E. M. A. Mokheimer, "Comparative Analysis of Different Inlet Air Cooling Technologies Including Solar Energy to Boost Gas Turbine Combined Cycles in Hot Regions," J. Energy Resour. Technol., vol. 140, no. 11, Jun. 2018, doi: 10.1115/1.4040195.

[25] W. Bou Nader, F. Breque, Y. Mazloum, C. Dumand, and M. Nemer, "Dynamic Modeling and Fuel Consumption Potential of an Intercooled Regenerative Reheat Gas Turbine Auxiliary Power Unit on Series Hybrid Electric Vehicle," J. Energy Resour. Technol., vol. 142, no. 1, Sep. 2019, doi: 10.1115/1.4044366.

[26] Y. S. H. Najjar and A. M. Abubaker, "Thermoeconomic analysis and optimization of a novel inlet air cooling system with gas turbine engines using cascaded waste-heat recovery," Energy, vol. 128, pp. 421-434, 2017, doi: https://doi.org/10.1016/j.energy.2017.04.029.

[27] M. Morini, M. Pinelli, P. R. Spina, A. Vaccari, and M. Venturini, "Feasibility analysis of gas turbine inlet air cooling by means of liquid nitrogen evaporation for IGCC power augmentation," Appl. Therm. Eng., vol. 80, pp. 168-177, 2015, doi: https://doi.org/10.1016/j.applthermaleng.2015.01.0 25.

[28] S. S. Baakeem, J. Orfi, and H. Al-Ansary, "Performance improvement of gas turbine power plants by utilizing turbine inlet air-cooling (TIAC) technologies in Riyadh, Saudi Arabia," Appl. Therm. Eng., vol. 138, pp. 417-432, 2018, doi: 
https://doi.org/10.1016/j.applthermaleng.2018.04.018.

[29] V. Mazhari, S. Khamis Abadi, H. Ghalami, M. H. Khoshgoftar Manesh, and M. Amidpour, "TechnoEconomic Evaluation of Using Different Air Inlet Cooling Systems in Gas Compressor Station," in Advances in Gas Processing, vol. 3, A. Aroussi and F. B. T.-P. of the 3rd G. P. S. Benyahia, Eds. Oxford: Elsevier, 2012, pp. 295-302.

[30] M. H. Khoshgoftarmanesh, H. Vazini Modabber, and V. Mazhari, "Techno-Economic Assessment of Different Inlet Air Cooling Systems in Warm Dry \&amp; Wet Climate Stations," Gas Process. J., vol. 4, no. 2, pp. 19-31, 2016, doi: 10.22108/gpj.2017.100042.1001.

[31] H. M. Kwon, T. S. Kim, J. L. Sohn, and D. W. Kang, "Performance improvement of gas turbine combined cycle power plant by dual cooling of the inlet air and turbine coolant using an absorption chiller," Energy, vol. 163, pp. 1050-1061, 2018, doi: https://doi.org/10.1016/j.energy.2018.08.191.

[32] H. Sadighi Dizaji, E. J. Hu, L. Chen, and S. Pourhedayat, "Using novel integrated Maisotsenko cooler and absorption chiller for cooling of gas turbine inlet air," Energy Convers. Manag., vol. 195, pp. 1067-1078, 2019, doi: https://doi.org/10.1016/j.enconman.2019.05.064.

[33] M. R. Majdi Yazdi, F. Ommi, M. A. Ehyaei, and M. A. Rosen, "Comparison of gas turbine inlet air cooling systems for several climates in Iran using energy, exergy, economic, and environmental (4E) analyses," Energy Convers. Manag., vol. 216, p. 112944, 2020, doi: https://doi.org/10.1016/j.enconman.2020.112944.

[34] S.-H. Cha, S.-I. Na, Y. H. Lee, and M. S. Kim, "Thermodynamic analysis of a gas turbine inlet air cooling and recovering system in gas turbine and $\mathrm{CO} 2$ combined cycle using cold energy from LNG terminal," Energy Convers. Manag., vol. 230, p. 113802, 2021, doi: https://doi.org/10.1016/j.enconman.2020.113802.

[35] M. B. Hashmi, M. A. A. Majid, and T. A. Lemma, "Combined effect of inlet air cooling and fouling on performance of variable geometry industrial gas turbines," Alexandria Eng. J., vol. 59, no. 3, pp. 1811-1821, 2020, doi: https://doi.org/10.1016/j.aej.2020.04.050. 